\title{
PENSAR A DEFICIÊNCIA A PARTIR DOS MODELOS MÉDICO, SOCIAL E PÓS-SOCIAL
}

\section{THINKING ABOUT DISABILITY CONSIDERING THE MEDICAL, SOCIAL AND POST-SOCIAL MODELS}

\section{PENSAR LA DISCAPACIDAD A PARTIR DE LOS MODELOS MÉDICO, SOCIAL Y POS-SOCIAL}

\author{
Cláudia Alquati Bisol \\ Doutora em Psicologia. Curso de Psicologia e Programa de Pós-Graduação em \\ Educação da Universidade de Caxias do Sul, RS. \\ Caxias do Sul - RS, Brasil. \\ claubisol@gmail.com \\ Nicole Naji Pegorini \\ Graduada em Psicologia pela Universidade de Caxias do Sul, RS. \\ Caxias do Sul - RS, Brasil. \\ nnparvati@gmail.com \\ Carla Beatris Valentini \\ Doutora em Informática na Educação. Curso de Pedagogia e \\ Programa de Pós-Graduação em Educaçãonda Universidade de Caxias do Sul, RS. \\ Caxias do Sul-RS, Brasil \\ carlabeam@gmail.com
}

RESUMO: Nos estudos relacionados à deficiência, podem-se identificar com clareza duas perspectivas paradigmáticas que fundamentam as ideias e ações de pesquisadores e profissionais a partir da modernidade: o modelo médico e o modelo social. Atualmente, no entanto, percebe-se a emergência de críticas ao modelo social que se encaminham para o que possivelmente poderá se constituir em uma terceira perspectiva (denominada neste trabalho de pós-social). O presente artigo tem por objetivo analisar princípios que norteiam a compreensão da deficiência considerando essas três perspectivas. Foram selecionadas publicações realizadas a partir da década de 1990 no Brasil, Europa Ocidental e América do Norte, utilizando-se os descritores inclusão escolar, sociedade inclusiva, direitos humanos e políticas públicas para pessoas com deficiência, paradigmas da deficiência, modelo médico, modelo social, estudos da deficiência e estudos feministas. Traçaram-se reflexões sobre os modelos por meio da identificação dos contextos sócio-históricos e das bases epistemológicas que os sustentam, e de algumas articulações com o campo da educação especial na perspectiva da inclusão. Problematizar esses modelos que coabitam os espaços sociais permite deslocamentos que possibilitem repensar as relações com a pessoa com deficiência nos diferentes contextos e instituições.

PALAVRAS-CHAVE: Educação inclusiva. Estudos da deficiência. Modelo médico. Modelo social.

ABSTRACT: In the disability-related studies, one can clearly identify two paradigmatic perspectives which underlie researchers and professionals' ideas and actions from Modernity onwards: the medical model and the social model. Currently, however, we see the emergence of critiques regarding the social model moving towards what could possibly constitute a third perspective (called post-social in this paper). The present article aims to analyze the principles which guide the understanding of disability considering these three perspectives. Publications carried out from the 1990s in Brazil, Western Europe and North America were selected using the descriptors school inclusion, inclusive society, human rights and public policies for people with disabilities, disability paradigms, medical model, social model, disability studies and feminist studies. We attempted to trace reflections on the models by identifying the socio-historical contexts and the epistemological foundations that support them and by some articulations with the field of special education in the perspective of inclusion. To problematize these models which coexist in social spaces allows for shifts that may enable to rethink our relations with persons with disabilities in different contexts and institutions.

KEYWORDS: Inclusive education. Disability studies. Medical model. Social model.

Artigo recebido em janeiro de 2017

Aprovado em março de 2017 
RESUMEN: En los estudios relacionados con la discapacidad, se puede identificar con claridad dos perspectivas paradigmáticas que fundamentan las ideas y las acciones de los investigadores y profesionales a partir de la Modernidad: el modelo médico y el modelo social. Actualmente, sin embargo, se puede percibir la emergencia de críticas al modelo social que conducen a lo que posiblemente podrá constituirse en una tercera perspectiva (denominada en ese trabajo de pos-social). El presente artículo tiene como objetivo analizar los principios que embasan la comprensión de la discapacidad considerando esas tres perspectivas. Fueron seleccionadas publicaciones realizadas a partir de la década de 1990 en Brasil, Europa Occidental e América del Norte, utilizando los descriptores inclusión escolar, sociedad inclusiva, derechos humanos y políticas públicas para personas con discapacidad, paradigmas de la discapacidad, modelo médico, modelo social, estudios de discapacidad y estudios feministas. Se buscó trazar reflexiones sobre los modelos a través de la identificación de los contextos socio-históricos y de las bases epistemológicas que los sostienen, y de articulaciones con el campo de la educación especial en la perspectiva de la inclusión. Problematizar eses modelos que cohabitan los espacios sociales permite desplazamientos que posibiliten repensar las relaciones con la persona con discapacidad en los diferentes contextos e instituciones.

PALABRAS CLAVE: Educación inclusiva. Estudios de discapacidad. Modelo médico. Modelo social. 
PENSAR A DEFICIÊNCIA | Cláudia Alquati Bisol, Nicole Naji Pegorini e Carla Beatris Valentini

\section{1| INTRODUÇÃO}

Em "A estrutura das revoluções científicas", livro publicado pelo físico e filósofo Thomas Kuhn em 1962, a racionalidade científica é descrita como instável e em constante transformação, um processo influenciado por variáveis históricas, culturais e subjetivas que permeiam a vida humana em sociedade. A ciência, assim compreendida, não diz respeito a uma lógica estática e completamente objetiva ou neutra, mas vem servir a um propósito de seu tempo, buscando explicar ou resolver questões da natureza que se impõem ao homem (OLIVA, 1999).

O conceito de paradigma é central nas reflexões de Kuhn. Para o autor, paradigmas são "realizações científicas universalmente reconhecidas que, durante algum tempo, fornecem problemas e soluções modelares para uma comunidade de praticantes de uma ciência" (KUHN, 2007, p. 13). Desta forma, pode-se dizer que cada modelo de ciência nasce para servir à realidade de uma dada época em um determinado contexto, fundamentando novas ideias, perspectivas e referenciais de ação. Na medida em que novas urgências surgem, novas maneiras de fazer ciência se desenvolvem. Assim, um paradigma consolidado em um período poderá ser reeditado, modificado ou substituído a partir de novas descobertas e com o avanço das pesquisas.

Portanto, as mudanças no campo da ciência ou as chamadas "revoluções científicas", como descritas por Kuhn (2007), dizem respeito a um movimento inevitável de reformulação epistemológica que ocorre quando um sistema paradigmático falha na compreensão do mundo que nos cerca, ou ainda, falha em resolver o problema primário para o qual foi desenvolvido. Assim, iniciase um novo momento científico que gera investigações e formulações teóricas para dar conta dos novos problemas que se apresentam. Um novo paradigma se consolida quando um número considerável de cientistas concorda com as bases da nova teoria e se sua aplicabilidade condiz com os dados de realidade, e podem trazer benefícios à organização social vigente (CHALMERS, 1993).

Em relação à deficiência, pode-se identificar com clareza duas perspectivas paradigmáticas que fundamentam as ideias e referenciais de ação de pesquisadores e profissionais a partir da modernidade: as perspectivas comumente denominadas de modelo médico e de modelo social (OLIVER, 1999b; BARNES, 2012). Mais recentemente, percebe-se a emergência de uma terceira perspectiva que tem influenciado a produção científica principalmente europeia e norte-americana. Alguns autores denominam esta perspectiva de crítica ao modelo social (CROW, 1992; SHAKESPEARE, 1996; MORRIS, 1991; BARNES, 2012; GOODLEY, 2013). Outros autores argumentam que se trata de uma segunda geração do modelo social (DINIZ, 2007; MELLO; NUERNBERG, 2012). E alguns outros ainda, chegam a apresentar esta nova perspectiva como um novo paradigma ou modelo, que poderia ser denominado de pós-social (SHAKESPEARE, 1996, 2002; MARTIN, 2011) ou pós-moderno (CARLSON, 2010).

O presente trabalho tem por objetivo analisar princípios que norteiam a compreensão da deficiência a partir dos modelos médico, social e pós-social ${ }^{1}$. Para tanto, foi realizada uma revisão da literatura especializada, por meio de consulta a livros e periódicos publicados a partir da década de 1990 no Brasil, Europa Ocidental e América do Norte, disponíveis na biblioteca da Universidade de Caxias do Sul (UCS) e artigos científicos selecionados por meio de busca no banco de dados do Scielo, portal BVS psicologia, LILACS e portal de periódicos CAPES. A busca nos bancos de dados utilizou os descritores inclusão escolar, sociedade inclusiva, direitos humanos e políticas para pessoas com deficiência, paradigmas da deficiência, modelo médico, modelo so cial, estudos da deficiência e estudos feministas. Foram incluídos os estudos que apresentavam

\footnotetext{
${ }^{1}$ A denominação de modelo pós-social foi escolhida a fim de facilitar as referências à mudança que se percebe no modelo social. Ressalta-se que não há ainda um consenso em relação a esta denominação.
} 
PENSAR A DEFICIÊNCIA | Cláudia Alquati Bisol, Nicole Naji Pegorini e Carla Beatris Valentini

discussões epistemológicas, comparações entre os modelos de deficiência, posicionamentos teórico-críticos sobre os modelos e transversalidade com os estudos feministas. Foram excluídos os estudos que não apresentavam aprofundamento teórico ou cuja revisão crítica acerca dos modelos não fosse o foco. Traçaram-se reflexões sobre os modelos por meio da identificação do contexto sócio-histórico e das bases epistemológicas que os sustentaram e de algumas articulações com o campo da educação especial na perspectiva da inclusão.

\section{2 | CONTEXTO SÓCIO-HISTÓRICO}

Observar os principais marcos sociais e históricos que caracterizam os momentos nos quais prevaleceram ou prevalecem determinadas ideias no campo da ciência, auxilia na compreensão das racionalidades subjacentes às abordagens que sustentam as tentativas de compreensão dos fenômenos. Algumas questões podem ser interessantes, tais como: qual o contexto que prevalecia no auge do modelo médico? Quais as forças sociais relacionadas às mudanças trazidas pelo modelo social? Por que o modelo social não parece suficiente para responder às demandas da contemporaneidade?

Pode-se iniciar esta tentativa de apontar para alguma dessas respostas com Foucault (1977), segundo o qual a medicina moderna se estabeleceu no final do século XVIII e início do século XIX, amparada em princípios iluministas e positivistas e construindo um discurso de estrutura científica sobre o sujeito. Este discurso se estruturou com base em uma racionalidade que toma o indivíduo como objeto de estudo a partir de um olhar concreto, objetivo, que busca transformar a realidade em algo previsível e manipulável: a vida deixa de ser um mistério para se tornar objeto da lógica e da razão. Concepções religiosas de mundo cederam espaço para concepções científicas. Esta revolução paradigmática (retomando o termo de Kuhn [1962/2007]) é uma das bases da modernidade, tendo no modelo de racionalidade o estabelecimento das novas relações entre sujeito e objeto do conhecimento, principalmente a partir das ideias de Descartes e Bacon (MANCEBO, 2002).

A racionalidade médica moderna se voltou ao conhecimento do homem saudável e a uma definição de homem modelo, tomando uma postura normativa na gestão da existência humana. $A$ medicina passou então a distribuir conselhos e a reger as relações físicas e morais do indivíduo e da sociedade. A ciência e a tecnologia passaram a deter o saber e a usá-lo para manutenção e controle da vida privada por intermédio da esfera pública. Assim, as instituições de educação e saúde, por exemplo, foram se estruturando para servir a este propósito (FOUCAULT, 1977).

É importante situar que este mesmo momento histórico foi também marcado pela consolidação do capitalismo como modo de produção dominante, o qual não trouxe apenas transformações econômicas, mas também transformações nas relações políticas, sociais e na subjetivação dos homens. Estas transformações, segundo Mancebo (2002), colocaram o homem como centro do mundo, gerando certo censo de individualismo e independência que predominou no desenvolvimento social da época. Essas transformações, que se desenrolaram a partir do Renascimento e se fortaleceram com os ideais de liberdade e igualdade, geraram modificações de cunho político, religioso, cultural e no modo de fazer e pensar a ciência.

O capitalismo também firmou a importância do homem enquanto ser produtivo, capaz de trabalhar, gerar mais-valia e consumir. O corpo valorizado é o corpo capaz de se situar dentro deste circuito (MARTíN; CASTILLO, 2010). Há uma relação entre o desenvolvimento das ciências médicas no campo da deficiência e o avanço do sistema econômico capitalista impulsionado pela revolução industrial. Participar do mercado exige indivíduos ativos, aptos para o trabalho produtivo. A concepção de deficiência, dentro da racionalidade médica prevalecente neste momento histórico, acabou construindo associações entre desemprego, baixa escolaridade e segregação causadas 
PENSAR A DEFICIÊNCIA | Cláudia Alquati Bisol, Nicole Naji Pegorini e Carla Beatris Valentini

pela inabilidade do corpo com impedimentos ${ }^{2}$ para o trabalho produtivo (DINIZ; BARBOSA; SANTOS, 2009).

O século $X X$, por sua vez, foi fortemente marcado pelas duas grandes guerras mundiais e pelos avanços da medicina. Barnes (2012) menciona uma obrigação moral sentida por parte dos políticos e da população geral em relação ao grande número de civis e militares feridos nos campos de batalha, ao mesmo tempo em que a sociedade passou a perceber um crescimento inusitado no número de pessoas com deficiência e de pessoas idosas devido à melhoria das condições de vida e aos avanços da medicina. Novas demandas na área da saúde pública passaram a ser sentidas. Viu-se então o surgimento de serviços voluntários, especialização profissional, centros de atendimento, instituições, etc. No campo da deficiência, a medicina se consolidou como principal alternativa de intervenção, constituindo especializações e enfocando a reabilitação (OLIVER, 1999b; SILVA; DESSEN, 2001; MARTÍN; CASTILLO, 2010; FERREIRA, 2011). A medicina oferecia alternativas para lidar com as limitações físicas e/ou intelectuais, o que promoveu a ideia de que as pessoas com deficiência deveriam buscar tratamento e programas de reabilitação como solução para remover ou amenizar os danos corporais. A interpretação da deficiência como tragédia pessoal, como problema individual que causa dificuldades e desvantagens ao indivíduo reforçava esta lógica (CROW, 1992; OLIVER, 1999a; MARTíN; CASTILLO, 2010).

De acordo com Mancebo (2002), a modernidade foi um período de contradições: ao mesmo tempo em que houve a luta das classes marginalizadas e excluídas, obtiveram-se ganhos em termos de direitos nas áreas da educação, trabalho, saúde e segurança, com ideais de liberdade e independência. A segunda metade do século XX, particularmente as décadas de 1960, 1970 e 1980, trouxe os movimentos da contracultura, das minorais e a luta pela igualdade de direitos humanos, com fortes críticas aos preconceitos e discursos políticos até então vigentes (SHAKESPEARE, 2006; SAXTON, 2006; DAVIS, 2006a; DINIZ, 2007; DINIZ; BARBOSA; SANTOS, 2009; GOODLEY, 2013). Foi neste momento histórico, portanto, que emergiu e se consolidou uma nova perspectiva política, social e teórica em relação à deficiência, que passou ser chamada de modelo social. Sobre esses movimentos, Gusmão (2008) destaca que cada grupo minoritário buscava reivindicar sua própria identidade e seus direitos perante o Estado, que tinha e tem como tendência a homogeneização da realidade social. Trata-se de uma época de profundos questionamentos a respeito da opressão das minorias, com fortes oposições aos valores e normas vigentes, em que a contracultura congregou diversos movimentos de contestação social (MARTíN; CASTILLO, 2010).

A reação política em prol das pessoas com deficiência culminou em debates políticos e na ampliação dos estudos sobre deficiência nas academias (OLIVER, 1999b). A mobilização política e social também demandava a democratização e acesso aos recursos e tratamentos médicos. Formalizaram-se grupos e movimentos voltados ao campo da deficiência, sendo o modelo social corporificado por meio de diversas organizações acadêmicas, institucionais e políticas, tais como o UPIAS (Union of Physically Impaired Against Segregation), e se instituindo como oposição ao modelo anterior que então passou a ser amplamente denominado de modelo médico (SHAKESPEARE, 2006).

O período que se iniciou na segunda metade do século XX produziu modificações profundas na organização social, a ponto de se considerar o início do que muitos denominam de pós-modernidade. Segundo Coracini (2014), a pós-modernidade foi assim denominada inicialmente por Lyotard para referir à contemporaneidade e às mudanças que começaram a ser percebidas. Segundo a autora: "Essa visão trouxe mudanças políticas e ideológicas de grande porte, dentre as quais o descentramento da autoridade, a divisão de responsabilidades, a crença em verdades de

\footnotetext{
${ }^{2}$ Opta-se, neste texto, por traduzir o termo impairment como "impedimento", embora possa ser encontrado em outras publicações como lesão, incapacidade ou limitação.
} 
PENSAR A DEFICIÊNCIA | Cláudia Alquati Bisol, Nicole Naji Pegorini e Carla Beatris Valentini

um dado momento histórico-social, e não em uma verdade, universal e uma" (CORACINI, 2014, p. 401).

A pós-modernidade é marcada por uma configuração social global de diversidade e pluralidade, tranversalidades e multiculturalismo (CARLSON, 2010); de heterogeneidade, sujeito múltiplo e ecletismo (CORACINI, 2014). Neste sentido, o tema da deficiência passa a ser compreendido em interface com diversas áreas de saber que não exclusivamente o médico ou o social (DINIZ, 2007; GOODLEY, 2013).

No final do século $X X$ e início do século $X X I$, percebem-se transformações importantes que provocam críticas ao modelo social e situam o que talvez possa se consolidar como um novo modelo, o pós-social. Como citado anteriormente, estas críticas têm recebido diferentes nomenclaturas: crítica ao modelo social, segunda geração do modelo social, revisão do modelo social, modelo pós-social (SHAKESPEARE, 1996, 2002; DAVIS, 2006b; DINIZ, 2007; CARLSON, 2010; GOODLEY, 2013). Nesta nova perspectiva surge também o que alguns autores denominam estudos críticos da deficiência (Critical Disability Studies).

Goodley associa uma mudança nos estudos sobre deficiência a partir deste novo momento social e histórico, no qual se luta pelo reconhecimento de outras possibilidades trazidas pelo feminismo, estudos críticos da raça, marxismo e teoria queer, por meio das quais se buscaria explorar a convergência e a divergência de múltiplos marcadores. "Isso envolve conversas difíceis entre categorias socioculturais e formas de interpelação para perguntar como, por exemplo, deficiência, sexo, raça, sexualidade e classe constituem ou contradizem um ao outro" (GOODLEY, 2013, p. 636, tradução nossa).

A pós-modernidade implica uma nova concepção de ser humano, de sociedade e de globalidade, permeada principalmente pela complexidade que a atualidade impõe. Trata-se de um período de diversidade, e esse novo contexto contribui para mudanças na produção científica e nas perspectivas sociais a respeito dos fenômenos culturais.

\section{3 | BASES EPISTEMOLÓGICAS DOS MODELOS MÉDICO, SOCIAL E PÓS-SOCIAL}

A busca por uma compreensão acerca da racionalidade científica em torno da questão da deficiência passa, necessariamente, por uma reflexão de base epistemológica, pois "o epistemológico consiste nos pressupostos do conhecimento científico, no exame das justificações do conhecimento, nos critérios da demarcação científica do conhecimento" (PAVIANI, 2013, p. 11-12).

As bases epistemológicas do modelo médico foram os ideais iluministas que marcaram os séculos XVII, XVIII e XIX e que também serviram como influência filosófica na construção dos ideais científicos positivistas (FOUCAULT, 1977; CANGUILHEM, 2009; DAVIS, 2006a; SAFATLE, 2011; SHAKESPEARE, 1996, 2002).

O positivismo se caracteriza por propor pilares científicos que norteiam uma visão de mundo sustentada por princípios de objetividade, neutralidade, causalidade linear, racionalidade, metodologia científica, análise de fenômenos concretos e observáveis, razão produtiva, organicidade, entre outros. Tais princípios colocam o cientista na posição de que seria possível considerar uma única e verdadeira realidade e, a partir disso, buscar uma lógica racional que explique os fatos. Desta maneira é que padrões são reconhecidos e estabelecidos cientificamente (COMTE, 1990). Segundo Clavreul (1978), estes padrões direcionam a ordem médica, principalmente no que se refere à compreensão do patológico.

De acordo com Silva (1997), filósofos como Bacon (1561-1626), Descartes (1596-1650) e Kant (1724-1804) representam o cerne do paradigma científico moderno, em que a racionalidade pos- 
PENSAR A DEFICIÊNCIA | Cláudia Alquati Bisol, Nicole Naji Pegorini e Carla Beatris Valentini

sibilita ao homem dominar a natureza a partir da compreensão lógica, matemática e objetiva da realidade. A razão constitui o meio pelo qual o conhecimento se torna possível, mediante procedimentos e métodos que permitem a conformação dos fenômenos a uma definição prévia da ciência objetiva. A racionalidade e a metodologia oportunizaram o progresso iluminista em que o mito dá lugar à razão esclarecida.

Para o positivismo, a patologia está diretamente relacionada à fisiologia. A doença é qualquer alteração do estado normal ou natural, variando em níveis de intensidade, como excesso ou falta de algo. O estudo e sistematização das patologias refere-se à correlação entre os diversos estados anormais do organismo com seu estado padrão (CANGUILHEM, 2009). Clauvrel (1978, p. 39) argumenta que: "[...] a medicina pôde isolar o que constitui seu objeto: isto é, a doença, e fazer seu estudo considerando-a como semelhante em todos os homens, com exceção de algumas variantes que se relacionam tanto à própria doença quanto ao homem no qual ela evolui."

Por um lado, a racionalidade presente no discurso positivista, e que fundamenta o modelo médico, possibilitou superar as explicações religiosas e a medicina empírica sem expressão científica que prevalecia até o momento (OLIVEIRA, 2006). É a racionalidade médica que permite que o olhar para a deficiência perca seu cunho caritativo e religioso. O que antes era considerado como "diabólico" ou como castigo divino, passou a ser chamado de doença ou anormalidade (FOUCAULT, 1977).

Por outro lado, o modelo médico focado nas questões fisiológicas objetiva restaurar o corpo doente à condição considerada normal. A deficiência, vista enquanto desvio do estado normal da natureza humana, deve ser tratada e amenizada. Os esforços para reparar os impedimentos corporais e as desvantagens naturais visam que as pessoas possam se adequar a um padrão de funcionamento típico da espécie (DINIZ; BARBOSA; SANTOS, 2009). Michael Oliver foi um dos primeiros a propor, no início dos anos 1980, uma distinção binária entre duas formas de compreender a deficiência, preferindo nomear de modelo individual e modelo social. Ao modelo individual, o autor atribuiu a tendência de situar o problema no indivíduo, na medicalização e na atribuição das causas dos problemas deste individuo a seus impedimentos e perdas psicológicas, que por sua vez seriam derivadas da deficiência. Como pano de fundo, uma visão de deficiência como tragédia pessoal que a coloca como um evento que acomete aleatoriamente alguns indivíduos desafortunados (OLIVER, 2009).

O modelo social, por sua vez, surgiu como uma crítica a este modo de pensar que norteava a ciência. Como afirma Oliveira (2011, p. 146),

da recusa da cultura dominante e da crítica ao establishment ou sistema, brotaram novos significados: um novo modo de pensar, de encarar o mundo, de se relacionar socialmente. Surgiu, na verdade, uma revolta que contestou a cultura ocidental em seu âmago: a racionalidade.

Portanto, o modelo social se constituiu em uma posição de crítica ao positivismo e aos pressupostos do modelo médico, alterando significativamente a compreensão de deficiência e diversidade. Segundo Shakespeare (2006), há uma diferença muito grande entre as perspectivas que atribuíam à deficiência explicações relacionadas à punição divina, carma ou falha moral, ou explicações baseadas em ideias pós-iluministas que enfatizavam o deficit biológico, da perspectiva alavancada pelos movimentos sociais em prol das pessoas com deficiência, que focaram sua atenção na opressão social, no discurso cultural e nas barreiras ambientais.

Segundo os teóricos do modelo social, a perspectiva positivista característica do modelo médico acabou atribuindo um sentido negativo às diferenças fisiológicas, morfológicas e/ou funcionais, em razão de uma normatividade conceitualmente estabelecida que considerava essas diferenças como doenças/anormalidades. A mudança de perspectiva proposta pelo modelo social apoia-se, 
PENSAR A DEFICIÊNCIA | Cláudia Alquati Bisol, Nicole Naji Pegorini e Carla Beatris Valentini

em contrapartida, na ideia de que as diferenças corporais, sensórias e intelectuais não constituem anomalias ou doenças, mas diferentes formas de funcionamento, de tal modo que não se pode predizer a existência de uma norma a todos os seres humanos (CANGUILHEM, 2009). Essa mudança de perspectiva permitiu aos teóricos do modelo social defender a ideia de que não se pode compreender o ser humano de forma isolada, individualizada, como se fosse a manifestação de um problema que deve ser corrigido para retornar à normalidade, mas como um ser em relação, que deve ser entendido como parte de um grupo social, de dada cultura, envolvido por uma história, constituído a partir de relações micro e macrossistêmicas (OLIVEIRA, 2011).

Enquanto o modelo médico se sustenta em bases positivistas, o modelo social se sustenta no materialismo histórico, trazendo o marxismo como forte influência crítica e argumentativa. Isso permitiu aos teóricos do modelo social argumentarem que o sistema econômico capitalista dá espaço apenas para que pessoas com corpos saudáveis, normais, aptos e habilidosos possam ascender no mercado de trabalho, sendo que as pessoas com corpos diferentes ou "anormais/ doentes" seriam incapazes de participar e produzir. Estudiosos e ativistas passaram a lutar para que as pessoas com deficiência pudessem participar efetivamente da sociedade, viver com independência, ter empregos produtivos e controle completo sobre suas vidas (SHAKESPEARE, 2006).

Há uma mudança grande de perspectiva quando se passa a considerar que os problemas das pessoas com deficiência são causados por falhas de uma sociedade que precisa mudar. Outro ponto relevante é a distinção proposta entre doença e deficiência, sendo que esta última requer mudanças no ambiente, e não intervenções médicas (OLIVER, 1999a).

Em síntese, o modelo social interpretou a deficiência como um produto de uma sociedade "descapacitante" ou "incapacitante", e não como resultado de uma patologia no corpo do indivíduo. Ser incapacitado pela sociedade relaciona-se diretamente com a discriminação, que restringe a participação das pessoas com deficiência no meio social. Portanto, pode-se perceber com clareza a diferença existente entre os dois modelos, a ponto de se poder falar, como propõem Martín e Castillo (2010), de uma "dicotomia teórica" entre o fisiológico e o social.

Porém, no final do século XX, observou-se um aumento do interesse nos estudos sobre deficiência e, com isso, algumas novidades teóricas começaram a se delinear. Este movimento envolveu diversas áreas do conhecimento, colocando o tema da deficiência sob olhares multidisciplinares e promovendo críticas e revisões. Conceitos fortemente estabelecidos dentro do modelo social começaram a ser questionados a partir de teorizações advindas do materialismo, dos estudos feministas, da ênfase à importância do corpo, de questões do self e do outro, etc. (GOODLEY, 2013).

Uma das críticas ao modelo social se refere à centralidade do materialismo histórico, embora este tenha sido importante para a compreensão da deficiência e para o empoderamento das pessoas com deficiência. A crítica direciona-se à supervalorização que esta perspectiva ganhou no modelo social (DINIZ; BARBOSA; SANTOS, 2009) e nas contribuições que as teorias pós-marxistas, tais como o pós-estruturalismo e o pós-colonialismo, podem trazer para a discussão em torno da deficiência (GOODLEY, 2013).

Segundo Shakespeare (2002), o valor do modelo social é enfatizar a opressão e a exclusão que haviam sido negligenciadas no modelo médico. A crítica incide sobre a necessidade de se retomar o papel que o corpo com limitações, tem na vida das pessoas com deficiência: "[...] às vezes parece que este foco é tão absoluto que nós corremos o risco de afirmar que os impedimentos não têm parte alguma em determinar nossas experiências. [...] por que os impedimentos foram tão excluídos de nossas análises?" (CROW, 1992, p. 03, tradução nossa).

Outra crítica importante se constrói a partir dos estudos feministas. Segundo Shakespeare (1999), feminilidade e deficiência estão relacionadas a partir da condição de "passividade" estabe lecida pelos estereótipos sociais. Neste sentido, pode-se argumentar que as mulheres sofrem uma 
"dupla desvantagem", uma vez que a sociedade atual se estabeleceu permeada por estereótipos masculinos de "atividade, independência e produção" (DINIZ, 2007; DINIZ; BARBOSA; SANTOS, 2009; MELLO; NUERNBERG, 2012). Nesta abordagem crítica, autores apontam que a primeira geração de teóricos do modelo social teria sido formada, em sua maioria, por homens. Teóricas feministas denunciaram esses teóricos como pertencentes a uma elite dos deficientes, que tendiam, portanto a reproduzir discursos dominantes de gênero e classe (MELLO; NUERNBERG, 2012). A crítica de Shakespeare (2000, p. 159) se encaminha na mesma direção: "Foi sugerido, por feministas com deficiência tais como Jenny Morris, que os estudos sobre deficiência estavam reproduzindo o mesmo velho problema acadêmico de falar de pessoas com deficiência, quando na realidade eram questões relevantes apenas para homens com deficiência". Outro exemplo é o de Susan Wendell (2006, p. 244, tradução nossa):

Mulheres com deficiência lutam contra opressões por serem mulheres em uma sociedade dominada por homens e contra opressões por serem deficientes em uma sociedade dominada por corpos normais. Elas estão trazendo o conhecimento e as preocupações das mulheres com deficiência para o feminismo e as perspectivas feministas para os movimentos de direitos das pessoas com deficiência.

O modelo pós-social propõe uma maneira de olhar para a deficiência que é multidisciplinar, integrada, contextualizada e social. "Paralelos são traçados com as experiências das mulheres, lésbicas, gays e negros, e conceitos pós-estruturalistas são utilizados para problematizar a questão da identidade" (SHAKESPEARE, 1996, p. 94). Acrescentam-se outros componentes a essa perspectiva, que mantêm a reconceitualização da deficiência como uma forma de opressão social. Por exemplo, olhar para os deficientes severos, em que fatores importantes precisam ser considerados como a visão para além da independência, ou seja, a interdependência e a importância do cuidador e do lugar que este ocupa. Da mesma forma, à discussão da normalidade e da diversidade acrescenta-se o componente do corpo e da dor.

Entretanto, salienta-se que esse "novo modelo" ainda está em processo de constituição, fundamentando-se, atualmente, em críticas e reflexões acerca dos modelos anteriores e do contexto pós-moderno. De acordo com Goodley (2013), os estudos sobre deficiência estão se desenvolvendo em diferentes culturas e países, portanto os insights e críticas acerca da deficiência serão diferentes em cada região, uma vez que se trata de um assunto repleto de transversalidades e que se devem reconhecer as condições históricas e sociais específicas ao mesmo tempo em que se considera a globalização do deficientismo ${ }^{3}$.

\section{4 | A ESCOLA EM GERAL}

A racionalidade dominante em um determinado momento histórico pode ser observada nas diferentes instituições que organizam e regulamentam a vida em sociedade, a exemplo da escola. Pode-se observar, de forma muita clara, que a escola passou de um momento histórico no qual não havia lugar para as pessoas com deficiência a um momento, o atual, no qual a inclusão é mandatória. Traçar algumas articulações entre os modelos de deficiência e o campo da educação especial na perspectiva da inclusão pode contribuir para a compreensão do modo como a pessoa com deficiência pode ou não se situar no espaço escolar.

\footnotetext{
${ }^{3}$ Tradução do termo "disablism", conforme proposto por Sassaki (2014).
} 
PENSAR A DEFICIÊNCIA | Cláudia Alquati Bisol, Nicole Naji Pegorini e Carla Beatris Valentini

A racionalidade moderna sobre a qual se ergueu o sistema escolar foi caracterizada pelas ideias de uniformidade, meritocracia e formação de indivíduos úteis, hábeis para participar de uma sociedade pautada por padrões bem-estabelecidos:

As conclusões, já conhecidas, sobre a relação entre modernidade, educação e escola são evidentes: o tempo da modernidade e o tempo da escolarização insistem em ser, como decalques, temporalidades que só desejam a ordem, que teimam em classificar, em produzir mesmices homogêneas, íntegras, sem fissuras, a salvo de toda contaminação do outro. (SKLIAR, 2003, 45).

A escola não foi, por muito tempo, lugar para as diferenças. Espaços segregados foram criados para dar conta das pessoas com deficiência. As instituições asilares se configuraram como um dos destinos mais comuns, particularmente para aquelas pessoas cujas famílias não tinham condições de buscar auxílio particular a ponto de atingir algum grau de adequação que possibilitasse o convívio social. De um lado, asilos e classes especiais, grupos fechados para deficientes, de outro, o restante da sociedade ativa, normal, perfeita (GOODLEY, 2013).

Um exemplo importante é o nascimento das instituições para os "idiotas" e a aplicação de testes de Q.I. Nos Estados Unidos, as primeiras instituições abriram suas portas no final dos anos 1840. Eram instituições chamadas de escolas, asilos, ou simplesmente instituições que desempenhavam funções pedagógicas, médicas, terapêuticas, custodiais e profissionais, organizando princípios classificatórios, articulando teorias e propondo tratamentos. O modelo médico é explícito ao se considerar o papel que o superintendente desempenhava nessas instituições: o médico, homem, ao mesmo tempo administrador e pesquisador (CARLSON, 2010). No Brasil, a abertura do Imperial Instituto dos Meninos Cegos e, alguns anos depois, do Instituto dos Surdos-Mudos, data do mesmo período (anos 1850), reproduzindo características de internato comuns àquele período (JANUZZI, 2004).

Desde a Declaração de Salamanca (UNESCO, 1994), da qual o Brasil é signatário, o percurso em direção à consolidação de uma proposta de educação especial na perspectiva da inclusão foi longo. De espaços asilares e educativos segregados, ou espaços educativos segregados em escolas regulares (salas especiais), o país passou a propor a inclusão, influenciado de modo significativo pelo movimento pela inclusão escolar surgido nos Estados Unidos da década de 1990 (MENDES, 2006).

Estas mudanças, por um lado substanciais, não conseguiram alterar um fator de base para o qual Angelucci (2014) chama a atenção: o público-alvo da educação especial, mesmo na perspectiva da educação inclusiva, continua a ser determinado a partir da racionalidade médica. Prevalece ainda um olhar sobre as pessoas com deficiência que enfatiza a cura (pois expressam a anormalidade) ou a tolerância. Forja-se uma abstração da pessoa deficiente a partir da qual se designa todo um conjunto de pessoas a quem falta algo. A reabilitação, o uso de próteses, órteses, implantes, ainda são praticamente compulsórios para que se tornem o mais normal possível. "Permanece o fetiche do conserto de corpos e mentes. Medicalizamos a diferença corporal ou funcional. Patologizamos a diferença de relação com o corpo e com sua funcionalidade" (ANGELUCCI, 2014, p. 121). Quando as intervenções médicas não podem suprir as faltas que os indivíduos com impedimentos apresentam, a educação se apresenta como uma alternativa de recuperar o sujeito em desvantagem social (DINIZ; BARBOSA; SANTOS, 2009). Influenciada pelos ideais positivistas, a educação e as práticas pedagógicas teriam a capacidade de renovar e reorganizar a sociedade.

A presença ou até mesmo a submissão da educação à lógica médica pode ser vista a partir de alguns exemplos. Entre os mais contundentes, está o discurso recorrente nas escolas e nas situações de formação inicial e continuada de professores, que conhecer as causas, as características 
PENSAR A DEFICIÊNCIA | Cláudia Alquati Bisol, Nicole Naji Pegorini e Carla Beatris Valentini

e as comorbidades dos diferentes "quadros" será determinante para a escolarização de determinados estudantes. Professores têm sido chamados a entender as principais etiologias e características das doenças, síndromes ou transtornos que caracterizam seus alunos, mais do que a refletir sobre questões pedagógicas:

Suas idades, seus pertencimentos de classe, suas histórias de aprendizagem, suas formas de interação, seus vínculos familiares não contam. Mais do que isso: as diferentes maneiras como estruturam suas relações com o conhecimento e os diferentes saberes dos(as) educadores(as) sobre processos ensino-aprendizagem e estratégias de alfabetização e letramento, tudo isso, que constitui os saberes da Educação, deixa de ser importante. (ANGELUCCI, 2014, p. 124).

Outro exemplo interessante que denota a presença da racionalidade característica do modelo médico na educação é a Nota Técnica $n^{\circ} 4$, datada de 23 de janeiro de 2014. Nesta, o que se pode perceber é uma necessidade de afirmar o saber educacional no espaço escolar, diminuindo a imposição do discurso médico por meio de um artifício legal. A Nota Técnica se refere aos documentos escolares que servem de declaração dos alunos com deficiência, transtornos globais do desenvolvimento, altas habilidades/superdotação. O documento do Ministério da Educação esclarece que não é imprescindível a apresentação de laudo médico por parte desses alunos, podendo o professor do Atendimento Educacional Especializado se articular com profissionais da saúde e anexar o laudo médico, neste caso, ao Plano de Atendimento Educacional Especializado. A Nota Técnica, de modo interessante, explicita que:

Ressalte-se, por imperioso, que a elaboração desse estudo de caso, não está condicionada a existência de laudo médico do aluno, pois, é de cunho estritamente, educacional, a fim de que as estratégias pedagógicas e de acessibilidade possam ser adotadas pela escola, favorecendo as condições de participação e de aprendizagem. (BRASIL, 2014).

Pode-se concluir que o modelo médico tem uma presença marcante nos espaços e discursos escolares da pessoa com deficiência. No entanto, pode-se também reconhecer a importância do modelo social, pois o próprio movimento por uma educação inclusiva se consolidou como aplicação prática ao campo da educação do movimento mais amplo de inclusão social. A segregação sistemática de qualquer grupo se tornou uma prática intolerável desde que se iniciaram os movimentos sociais nos anos 1960, que conscientizaram a sociedade sobre a segregação e a marginalização (MENDES, 2006).

É na esteira do modelo social, portanto, que políticas, reivindicação de direitos, acessibilidade, lutas contra o preconceito e a discriminação entraram definitivamente no universo escolar. A Nota Técnica mencionada anteriormente pode ser vista como um forte indício da presença do modelo médico e, ao mesmo tempo, como um indício da influência do modelo social na problematização sobre o olhar que se dirige às pessoas com deficiência nos espaços escolares, pelos próprios profissionais da educação.

Talvez a escola esteja se tornando um lugar possível para as diferenças, ao menos em nível discursivo. Concretamente, matrícula e presença não são sinônimos de inclusão, de participação, de respeito, de acesso, e, muito menos, de aprendizagem. Alunos com deficiências e outros trans tornos do desenvolvimento estão sendo matriculados nas redes regulares de ensino, mesmo que estas apresentem recursos humanos e financeiros escassos.

De que modo o modelo pós-social poderá contribuir para o cenário da educação especial na perspectiva da inclusão, particularmente em nosso país? Ao propor a discussão do papel que o corpo com impedimentos tem na vida das pessoas com deficiência, o modelo pós-social contribui para repensar 
PENSAR A DEFICIÊNCIA | Cláudia Alquati Bisol, Nicole Naji Pegorini e Carla Beatris Valentini

questões como a dor, o cuidado e a interdependência, elementos essenciais para aprofundar a inclusão do estudante com deficiência severa. Qual o papel da escola na vida dessas pessoas? Será importante articular suas necessidades à realidade das escolas, assegurando o atendimento pedagógico individualizado e os recursos específicos que demandam (PLETSCH, 2011). Porém, será igualmente importante questionar as bases que sustentam a própria ideia de inclusão, assim como as estratégias possíveis entre o cuidar e o educar que esses estudantes demandam.

\section{5 | CONSIDERAÇÕES FINAIS}

A proposta deste artigo consistiu em refletir sobre os modelos que contribuíram para deflagrar as possibilidades de novas expressões e de novas lógicas, alterando formas de compreender os padrões e as relações com as pessoas com deficiência. Os modelos coabitam os espaços sociais. Problematizá-los permite abrir espaço para deslocamentos que possibilitem repensar as relações com o outro nos diferentes contextos e instituições.

Não obstante se constituírem diferentes maneiras de pensar a deficiência tomando a lógica dos modelos social e pós-social, o modelo médico ainda opera em muitos olhares e situações nas quais prevalece a busca pela normalidade e pela cura. Assim, se por um lado o modelo médico permitiu ir além da compaixão opressora que paternalisticamente buscava diminuir o infortúnio da pessoa com deficiência por meio da caridade, foram necessárias as rupturas provocadas pelo modelo social para que a sociedade passasse a refletir sobre as barreiras que ela mesma impõe para a pessoa com deficiência.

Nessa mesma direção, a emergência de um novo modelo evidencia que o modelo social, tal como foi concebido, está apresentando algumas lacunas para pensar a questão para a qual ele emergiu. Estamos em uma época em que é fácil levantar críticas às teorias e modelos, mas o desafio é compreender a realidade como um campo de possibilidades, em que pressupostos dualistas, universalizantes e totalizantes precisam ser questionados. Apontar para questões particulares e individuais como as experiências da dor, sofrimento e privação que o corpo pode impor à pessoa com deficiência ou, ainda, assinalar para novas relações, ainda não compreendidas em sua totalidade, parecem ser algumas das contribuições do modelo pós-social. Temos diversos e complexos desafios, por exemplo, a questão que a interdependência convoca, ou seja, dirigir o olhar para o cuidador no processo de inclusão, um novo elemento na relação educacional. Como esse papel se coloca? O que se espera dele e o que ele espera ao estar nesse lugar? Seria ele mais uma personagem invisível? No complexo processo de inclusão e escolarização o que estamos conseguindo perceber e o que não estamos conseguindo compreender ou construir como possibilidade? Cabe a todos os envolvidos a responsabilidade de atentar para as configurações que acarretam ou demandam aprofundamento no modo como os fenômenos são compreendidos e nas possibilidades que precisam ser construídas. 
PENSAR A DEFICIÊNCIA | Cláudia Alquati Bisol, Nicole Naji Pegorini e Carla Beatris Valentini

\section{Referências}

ANGELUCCI, C. B. Medicalização das diferenças funcionais: continuísmos nas justificativas de uma educação especial subordinada aos diagnósticos. Nuances: Estudos sobre Educação, São Paulo, v. 1, n. 25, p.116134, 2014.

BARNES, C. The social model of disability: valuable or irrelevant?. In: WATSON, N.; ROULSTONE, A.; THOMAS, C. The routledge handbook of disability studies. London: Routledge, 2012. p. 12-29.

BRASIL. Ministério da Educação. Secretaria de Educação Continuada, Alfabetização, Diversidade e Inclusão. Diretoria de Políticas de Educação Especial. Nota Técnica $n^{\circ}$ 04, de 23 de janeiro de 2014. Orientação quanto a documentos comprobatórios de alunos com deficiência, transtornos globais do desenvolvimento e altas habilidades/superdotação no Censo Escolar. Brasília, DF: MEC; SECADI; DPEE, 2014.

CANGUILHEM, G. O normal e o patológico. 6. ed. Rio de Janeiro: Editora Forense Universitária, 2009.

CARLSON, L. The faces of intellectual disability: philosophical relections. Bloomington: Indiana University Press, 2010.

CHALMERS, A. O que é ciência, afinal? São Paulo: Brasiliense, 1993.

CLAVREUL, J. A ordem médica. Rio de Janeiro: Editora Brasiliense, 1978.

COMTE, A. Discurso sobre o espírito positivo. São PauIo: M. Fontes, 1990.

CORACINI, M. J. R. F. Entre a modernidade e a pós-modernidade: discurso e ensino. Educação, Santa Maria-RS, v. 37, n. 3, p. 400-411, 2014.

CROW, L. Including all of our lives: renewing the social model of disability. In: MORRIS, J. (Ed.). Encounters with strangers: feminism and disability. London: Women's Press, 1992. p. 1-21.

DAVIS, L. J. Constructing normalcy: the bell curve, the novel, and the invention of the disabled body in the nineteenth century. In: (Ed.). The disability studies reader. 2. ed. London: Routledge, 2006a. p. 3-16.

DAVIS, L. J. The end of identity politics and the beginning of dismodernism: on disability as an unstable category. In: (Ed.). The disability studies reader. 2. ed. London: Routledge, 2006b. p. 231-242.

DINIZ, D. O que é deficiência? São Paulo: Brasiliense, 2007.
DINIZ, D.; BARBOSA, L.; SANTOS, W. R. dos. Deficiência, direitos humanos e justiça. SUR - Revista Internacional de Direitos Humanos, São Paulo, v. 6, n. 11, p. 65-77, 2009.

FERREIRA, M. A. V. Discapacidad, globalidad y educación: ¿una nueva "política del cuerpo"? Revista Latinoamericana de Estudios sobre Cuerpos, Emociones y Sociedad, Córdoba-AR, v. 6, n. 3, p. 6-19, 2011.

FOUCAULT, M. O nascimento da clínica. Rio de Janeiro: Forense Universitária, 1977.

GOODLEY, D. Dis/entangling critical disability studies. Disability \& Society, London-UK, v. 28, n. 5, p. 631-644, 2013.

GUSMÃO, N. M. M. de. Antropologia, estudos culturais e educação: desafios da modernidade. Pro-Posições, Campinas, v. 19, n. 3(57), p. 47-82, set./dez. 2008.

JANUZZI, G. S. de M. A educação do deficiente no Brasil: dos primórdios ao início do século XXI. São Paulo: Autores Associados, 2004.

KUHN, T. A estrutura das revoluções científicas. 9. ed. São Paulo: Perspectiva, 2007.

MANCEBO, D. Modernidade e produção de subjetividades: breve percurso histórico. Psicologia: Ciência e Profissão, Brasília, v. 22, n. 1, p. 100-111, 2002.

MARTÍN, M. T.; CASTILLO, F. G. Cuerpos, capacidades, exigencias funcionales... y otros lechos de Procusto. Política y Sociedad, Madrid, v. 47, n. 1, p. 67-83, 2010.

MARTIN, N. Disability identity-disability pride. Perspectives, London-UK, v. 16, n. 1, p. 14-18, 2011.

MELLO, A. G.; NUERNBERG, A. H. Gênero e deficiência: interseções e perspectivas. Revista Estudos Feministas, Florianópolis, v. 20, n. 3, p. 635-655, 2012.

MENDES, E. G. A radicalização do debate sobre inclusão escolar no Brasil. Revista Brasileira de Educação, Rio de Janeiro, v. 11, n. 33, p. 387-405, 2006.

MORRIS, J. Pride against prejudice: transforming attitudes to disability. London-UK: The Women's Press, 1991.

OLIVA, A. Ciência e sociedade: do consenso à revoIução. Porto Alegre: EDIPUCRS, 1999.

OLIVEIRA, C. C. de. Ser sóbrio e racional: os usos ambíguos da razão na literatura e dietética dos primórdios das luzes inglesas. Scientiae Studia, São Paulo, v. 4, n. 1, p. 83-99, 2006. 
PENSAR A DEFICIÊNCIA | Cláudia Alquati Bisol, Nicole Naji Pegorini e Carla Beatris Valentini

OLIVEIRA, W. V. de. A fabricação da loucura: contracultura e antipsiquiatria. História, Ciências, Saúde - Manguinhos, Rio de Janeiro, v. 18, n. 1, p. 141-154, 2011.

OLIVER, M. J. Capitalism, disability and ideology: a materialist critique of the normalization principle. In: FLYNN, R. J.; LEMAY, R. A. A quarter-century of normalization and social role valorization: evolution and impact. Ottawa: University of Ottawa Press, 1999a. Disponível em: <http://www.independentliving.org/docs3/oliver99. pdf>. Acesso em: 01 abr. 2016.

The disability movement and the professions. British Journal of Therapy and Rehabilitation, London UK, v. 6, n. 8, p. 377-379, 1999b.

OLIVER, M. The social model in context. In: TITCHKOSKY, T.; MICHALKO, R. (Ed.). Rethinking normalcy: a disability study reader. Toronto: Canadian Scholar's Press, 2009. p. 19-30.

PAVIANI, J. Epistemologia prática: ensino e conhecimento científico. 2. ed. Caxias do Sul: Educs, 2013.

PLETSCH, M. D. A dialética da inclusão/exclusão nas políticas educacionais para pessoas com deficiência: um balanço do governo Lula (2003-2010). Revista Teias, Rio de Janeiro, v. 12, n. 24, p. 39-55, 2011.

SAFATLE, V. O que é uma normatividade vital? Saúde e doença a partir de Georges Canguilhem. Scientle Studia, São Paulo, v. 9, n. 1, p. 11-27, 2011.

SASSAKI, R. K. Capacitismo, incapacitismo e deficientismo na contramão da inclusão. Reação: Revista Nacional de Reabilitação, São Paulo, v. 96, n. 17, p. 10-12, 2014. Disponível em: <http://www.revistareacao.com.br/ website>. Acesso em: 01 abr. 2016.

SAXTON, M. Disability rights and selective abortion. In: DAVIS, L. J. (Ed.). The disability studies reader. 2. ed. London: Routledge, 2006. p. 105-116.
SHAKESPEARE, T. Disability, identity and difference. In: BARNES, C.; MERCER, G. Exploring the divide: illness and disability. Leeds: The Disability Press, 1996. p. 94-113.

Disabled sexuality: toward rights and recognition. Sexuality and Disability, New York, v. 18, n. 3, p. 159-166, 2000.

The sexual politics of disabled masculinity. Sexuality and Disability, New York, v. 17, n. 1, p. 53-64, 1999.

. The social model of disability: an outdated ideology? Social Science and Disability, Filadélfia-EUA, v. 1, n. 2, p. 9-28, 2002.

The social model of disability. In: DAVIS, L. J. (Ed.). The disability studies reader. 2. ed. London: Routledge, 2006. p. 197-204.

SILVA, F. L. Conhecimento e razão instrumental. Psicologia USP, São Paulo, v. 8, n. 1, p. 11-31, 1997.

SILVA, N. L. P.; DESSEN, M. A. Deficiência mental e família: implicações para o desenvolvimento da criança. Psicologia: Teoria e Pesquisa, Brasília, v. 17, n. 2, p. 133-141, 2001.

SKLIAR, C. A educação e a pergunta pelos outros: diferença, alteridade, diversidade e os outros "outros". Ponto de Vista, Florianópolis, v. 1, n. 5, p. 37-49, 2003.

UNESCO. Declaração de Salamanca sobre princípios, políticas e práticas na área das necessidades educativas especiais. Salamanca-Espanha: UNESCO, 1994.

WENDELL, S. Toward a feminist theory of disability. In: DAVIS, L. J. (Ed.). The disability studies reader. 2. ed. London: Routledge, 2006. p. 243-256. 